\title{
Endoscopic ultrasound-guided fine-needle aspira- tion using 22- and 25-gauge needles alternately
}

During endoscopic ultrasound (EUS)guided fine-needle aspiration (FNA), the standard size of needle used is a 22-gauge needle. Larger needles have been used to obtain actual core tissue samples [1-3], but their has failed to significantly improve diagnostic accuracy for malignancy [2-4], except perhaps in the case of unusual histology [5]. On the contrary, a new, smaller-caliber (25-gauge) needle has been introduced to the market by Wilson-Cook Medical Inc. (WinstonSalem, North Carolina, USA). The purpose of this study was to compare the 22- and 25-gauge needles for adequacy of tissue acquisition and diagnostic yield.

The study was a retrospective review of all EUS-FNA procedures performed using 22- and 25-gauge needles alternately in the same patient. Of a total of 132 patients undergoing EUS, only 16 met the inclusion criteria. The mean age was 65.1 years. The cytotechnician was present during $75 \%$ of the procedures. The needle pass was considered by the endoscopist to be difficult in $37.5 \%$ vs. $25.0 \%$ of cases using the 22- and 25-gauge needles, respectively $(P=0.7)$. The specimen adequacy rates were: cytologic 68.6 vs. 56.3 $(P=0.7)$, and histologic $87.5 \%$ vs. $75.0 \%$ $(P=0.6)$ with 22 - and 25-gauge needles, respectively. Two patients were lost to follow-up. Out of the remaining $14 \mathrm{pa}-$ tients, a definitive diagnosis was obtained in $85.7 \%$ (22-gauge needle) and $50.0 \%$ (25-gauge needle) $(P=0.1)$. When 22and 25-gauge needles were combined, the cytologic and histologic yields, as well as the definitive diagnosis, were higher $(81.3 \%, 93.8 \%$, and $92.9 \%$, respectively). Hence, in conclusion we found no statistically significant difference between needle size despite a relatively easier pass with the 25-gauge needle and higher specimen adequacy and definitive diagnosis with the 22-gauge needle. Although we found the two needles to complement each other when used alternately in the same patient, the differences did not reach statistical significance due to the small number of cases. We recommend large prospective trials.

\section{Endoscopy_UCTN_Code_TTT_1AS_2AF}

\section{S. Iqbal ${ }^{1,2}$, R. N. Mir ${ }^{3}$, W. Sohn ${ }^{1}$}

1 Division of Gastroenterology, New York Methodist Hospital, Brooklyn, New York, USA

2 Division of Gastroenterology, Interfaith Medical Center, Brooklyn, New York, USA

3 Department of Pathology, New York Methodist Hospital, Brooklyn, New York, USA

\section{References}

1 Matsui M, Goto H, Niwa Y et al. Preliminary results of fine needle aspiration biopsy histology in upper gastrointestinal submucosal tumors. Endoscopy 1998; 30: 750-755

2 Binmoeller KF, Thul R, Rathod $V$ et al. Endoscopic ultrasound-guided 18-gauge, fine needle aspiration biopsy of the pancreas using a $2.8 \mathrm{~mm}$ channel convex array echoendoscope. Gastrointest Endosc 1998; 47: $121-127$

3 Levy MJ, Jondal ML, Clain J, Wiersema MJ. Preliminary experience with an EUS-guided trucut biopsy needle compared with EUSguided FNA. Gastrointest Endosc 2003; 57: $101-106$

4 Solmi L, Muratori R, Bacchini P et al. Comparison between echo-guided fine needle aspiration cytology and microhistology in diagnosing pancreatic masses. Surg Endosc 1992; 6: $222-224$

5 Binmoeller KF, Rathod VD. Difficult pancreatic mass FNA: tips for success. Gastrointest Endosc 2002; 56: S86-S93

\section{Bibliography}

DOI 10.1055/s-0028-1103444

Endoscopy 2009; 41: E87

(c) Georg Thieme Verlag KG Stuttgart · New York . ISSN 0013-726X

\section{Corresponding author}

S. Iqbal, MD

New York Methodist Hospital,

Division of Gastroenterology

753 Classon Ave, 7A

Brooklyn

NY 11238

USA

Fax: +1-718-780-3851

shahzad_iqbal@hotmail.com

Table 1 Comparison of 22- and 25-gauge needles with combined technique.

\begin{tabular}{|c|c|c|c|c|c|c|c|}
\hline & \multicolumn{2}{|c|}{ 22-gauge needle } & \multicolumn{2}{|c|}{ 25-gauge needle } & \multicolumn{2}{|c|}{ Combined } & \multirow[t]{2}{*}{$P$-value } \\
\hline & $n / N$ & $\%$ & $n / N$ & $\%$ & $n / N$ & $\%$ & \\
\hline Tissue yield & $16 / 16$ & 100 & $15 / 16$ & 93.6 & $16 / 16$ & 100 & NS \\
\hline Difficult needle pass & $6 / 16$ & 37.5 & $4 / 16$ & 25.0 & N/A & & NS \\
\hline Cytologic adequacy & $11 / 16$ & 68.6 & $9 / 16$ & 56.3 & $13 / 16$ & 81.3 & NS \\
\hline Histologic adequacy & $14 / 16$ & 87.5 & $12 / 16$ & 75.0 & $15 / 16$ & 93.8 & NS \\
\hline Definitive diagnosis & $12 / 14$ & 85.7 & $7 / 14$ & 50.0 & $13 / 14$ & 92.9 & NS \\
\hline
\end{tabular}

N/A, not applicable; NS, not significant. 